\title{
The antemortem diagnosis of pyogenic liver abscess due to perforation of the gut by a foreign body
}

\author{
PAMEla J. SHAW \\ M.B.B.S., M.R.C.P.
}

\author{
J. G. FREEMAN* \\ M.B.B.S., M.R.C.P.
}

Department of Medicine, Dryburn Hospital, Durham

\begin{abstract}
Summary
Perforation of the gastrointestinal tract by ingested foreign bodies is rare; the diagnosis of pyogenic liver abscess resulting from such perforations is usually made at post-mortem. We present a case of perforation of the gut, due to an ingested dental plate, with a resultant pyogenic liver abscess, which presented as a pyrexia of unknown origin.
\end{abstract}

KEY WORDS: foreign body, liver abscess, perforation of gut.

\section{Introduction}

Pyogenic liver abscesses are uncommon in Western countries. Recent studies suggest that the incidence of pyogenic liver abscess is of the order of $0.3 / 1000$ (Perera, Kirk and Noone, 1980). However, liver abscesses carry a significant mortality and, especially if single, are sometimes only diagnosed at postmortem (Pyrtek and Bartus, 1956). The cardinal features of abdominal pain, a tender liver and fever are not always present (Leading article, 1980). Pyrexia of unknown origin is a common mode of presentation accounting for a third of one series of cases (Butler and McCarthy, 1969). Surgical drainage was widely regarded as the management of choice in pyogenic liver abscesses. However, recent reports have shown that under ultrasound control, percutaneous drainage of the abscess in combination with antibiotics is just as effective (Herbert et al., 1982; Perera et al., 1980). The source of the abscess is also changing. At one time the most common known cause of pyogenic liver abscess was appendicitis (Oshner, De Bakey and Murray, 1938), but more recent studies suggest that the biliary tract is now a more common source of the infection (De La Maza, Naeim and Berman, 1974; Lazerchick et al., 1973). As a cause of pyogenic liver abscess, foreign body perforation of the gut is exceedingly rare and

\footnotetext{
* Present address: Department of Gastroenterology, Royal Victoria Infirmary. Newcastle upon Tyne NEI 4LP.
}

antemortem diagnosis has been reported only once before (Lawthorne and Schaff, 1979). We report a second case where the diagnosis was made antemortem and which presented as a pyrexia of unknown origin.

\section{Case report}

A 39-year-old man was admitted in December 1981. Four weeks before admission he had developed an influenza-like illness with malaise, anorexia and vomiting. Following this he developed episodes of sweating and intermittent diarrhoea. He had loose bowel motions up to 3 times daily without any accompanying abdominal pain. He had not passed blood or mucus per rectum. The diarrhoea had largely resolved by the time of admission.

On examination, the patient was grossly obese and looked unwell. He had a fluctuating pyrexia of up to $39.0^{\circ} \mathrm{C}$. Abdominal examination revealed no tenderness, masses or organomegaly and the bowel sounds were normal. The respiratory and nervous systems were clinically normal.

Investigations showed white cell count $18.0 \times 10^{9} /$ litre ( $75 \%$ neutrophils), and an erythrocyte sedimentation rate of $118 \mathrm{~mm}$ in the first hour; liver function tests revealed an alkaline phosphatase of 184.6 IU/litre (normal range 20-95 IU/litre) and a gamma glutamyl transpeptidase of 347 IU/litre (normal range 10-48 IU/litre).

Ultrasound scan of the abdomen revealed a $10 \mathrm{~cm}$ cystic mass lying in the right lobe of the liver and pushing down the right kidney. Isotope liver scan showed a large filling defect in the right lobe of the liver. In view of these findings, laparotomy was performed. A mass was found attached to the upper pole of the right kidney and involving virtually all of the right lobe of the liver. Approximately one litre of pus was aspirated from the mass. Further exploration revealed a per-colic abscess secondary to perforation of the descending colon by a dental plate bearing 2 
incisor teeth. The abscesses were drained and a transverse colostomy was performed. A non-haemolytic streptococcus was grown from the aspirated pus and the patient was put on parenteral penicillin following surgery. He made an excellent postoperative recovery.

Following the operation, the patient told us that he had attended the Casualty Department 4 months previously because he feared he had swallowed his partial denture the previous evening while inebriated. Abdominal radiographs at that time had revealed no abnormality and the patient had been reassured.

\section{Comment}

Eighty to ninety per cent of swallowed foreign bodies pass through the gut without causing any intestinal damage (McPherson, Karlan and Williams, 1957). The reported incidence of intestinal perforation is less than 1\% (Perelman, 1962).

There have been approximately 300 reported cases of perforation of the gastrointestinal tract by ingested foreign bodies since the initial report of Mitchell (1899). In 6 cases, there was an associated pyogenic liver abscess usually due to penetration of the foreign body through the pyloroduodenal region with migration into the liver. However, we have found only one previous report of foreign body perforation of the gut with associated liver abscess diagnosed antemortem (Lawthorne and Schaff, 1979).

Several features of this case are worth stressing. Firstly, the long asymptomatic interval between ingestion of the denture and the appearance of symptoms. Secondly, the lack of prominent localizing signs on examination of the patient. Thirdly, the patient suffered considerable morbidity which could have been avoided if his denture had been radio- opaque. We would reiterate the plea of other authörs for the use of radio-opaque material in denture base construction.

\section{Acknowledgments}

We would like to thank Dr G. Terry and Mr D. W. Herring of Dryburn Hospital, Durham, for permission to report their patiefit.

\section{References}

BUtLER, T.J. \& MCCARTHY, C.F. (1969) Pyogenic liver abscess. 囱t, $10,389$.

De La Maza, L.M., Naeim, F. \& Berman, L.D. (1974) The changing aetiology of liver abscess. Further observations. Jou f $_{\text {gal }}$ of the American Medical Association, 227, 161.

Herbert, D.A., Fogel, D.A., Rothman, J., Wilson, S., Simmoqus, F. \& RUSKIN, J. (1982) Pyogenic liver abscesses: successful nensurgical therapy. Lancet, i, 134.

LAWTHORNE, T.W. \& SCHAFF, H.V. (1979) Occult liver abscess afd foreign body perforation of the bowel. American Journalegf Surgery, 45, 659.

Lazarchick, J., De Souza E Sihra, N.A., Nichols, D.R. Washington, J.A. (1973) Pyogenic liver abscess. Mayo Clicic Proceedings, 48, 349.

LEADING ARTICLE (1980) Pyogenic liver abscess. British Medital Journal, 1, 1155.

MCPHERSON, R.C., Karlan, M. \& Williams, R.D. (1957) Forergn body perforation of the intestinal tract. American Journak of Surgery, 94, 564.

MitCHELL, J.F. (1899) The presence of foreign bodies $8 \overrightarrow{80}$ vermiform appendix with especial reference to pointed todites. Bulletin of the Johns Hopkins Hospital, 10, 35.

PERELMAN, H. (1962) Toothpick perforations of the gastroin tital tract. Journal of Abdominal Surgery, 4, 51.

Perera, M.R., KIRK, A. \& NoONE, P. (1980) Presentation, diagn and management of liver abscess. Lancet, ii, 629.

PYRTEK, L. \& BARTUS, S.A. (1956) Hepatic pyaemia. New Engl@̈. Journal of Medicine, 272, 551.

Oshner, A., De BaKey, M. \& Murray, S. (1938). Pyogegic abscesses of liver II; analysis of 47 cases with review of literatufe. American Journal of Surgery, 40, 292.

(Accepted 18 November 1982) 